\title{
Enabling Cost Innovation by Non-Traditional Organizational Processes: the case of Chinese firms
}

\author{
Abstract \\ Cost innovation has emerged as a new pattern of innovation in recent years. The extant \\ literature has studied the preconditions for cost innovation to arise, including the availability \\ of low-cost talent at all skill levels, state assets and intellectual property at a discount, \\ management autonomy, and strong personal incentives to create value. Much less attention \\ has been paid to the role of organizational processes. In this research, based on a set of \\ Chinese firms, we investigate how non-traditional organizational processes can foster cost \\ innovation. We find that the adoption of new or unconventional organizational processes \\ facilitates the realization of various kinds of cost innovation. Specifically, searching \\ innovation ideas using customer-oriented processes, selecting by pragmatic decision making, \\ and implementing through flexible product development processes, all appear to underpin \\ and facilitate cost innovation in our sample of firms. These findings have important \\ implications for firms wishing to fuel cost innovation.
}

\section{Keywords}

Cost innovation; Organizational processes; Emerging markets 


\section{Introduction}

In recent years, a new pattern of innovation - subsequently termed cost innovation has emerged in many developing countries (Ernst et al., 2015; Pandit et al., 2018; Prabhu and Jain, 2015; Radjou et al., 2012; Williamson, 2009; Zeng and Williamson, 2007). The concept of cost innovation was first coined by Zeng and Williamson (2007), who defined it as "the strategy of using Chinese cost advantage in radically new ways to offer customers around the world dramatically more for less" (P1). They identified three vectors of cost innovation: 1) offering customers high technology at low cost; 2) presenting customers with an unmatched choice of products in what used be considered standardized, mass-market segments; and 3) offering specialty products at dramatically lower prices, turning them into volume businesses.

Cost innovation challenges two of the classic generic strategies - differentiation and focus (Porter, 1980) - for competing with low-cost competitors (Williamson, 2010). Those pursuing technological differentiation often target the most demanding users by providing the latest high technology products at high cost. Likewise, differentiation based on offering more variety and customer choice usually involves asking customers to pay a substantial price premium to make the business strategy feasible. The focus strategy, meanwhile, usually targets a niche market with a specialized offering that appeals to those customers who are willing to pay a price premium for a non-standard specification. Cost innovation strategy challenges these differentiation and focus strategies by offering high technology, variety, and customization of products to customers at dramatically lower prices.

The concept has been termed jugaad in the Indian context and also referred to as frugal innovation or frugal engineering (Prabhu and Jain, 2015; Radjou et al., 2012). Jugaad is a Hindi word meaning an improvised solution born from ingenuity and cleverness, which is a bottom-up approach to frugal and flexible innovation (Radjou et al., 2012). There are six 
underlying principles of jugaad innovation: seek opportunity in adversity; do more with less; think and act flexibly; keep it simple; include the margin; and follow your heart (Radjou et al., 2012). According to Radjou, Prabhu, and Ahuja (2012), jugaad innovation has led to dramatic growth from products that embody it in India.

Firms from other emerging markets, such as Brazil, Russia, Mexico, and Argentina, have adopted similar approaches to innovation (Guillen and Garcia-Canal, 2012). Highprofile examples include Brazil's Embraer in regional jets, Russia's Gazprom in energy, Mexico's Cemex in cement, and Argentina's Tenaris in seamless tubes. These firms have not only survived a fierce battle against established multinationals for home markets, they have also expanded internationally, through exports and foreign direct investment (FDI), to become multinational enterprises in their own right (Ramamurti, 2009).

Even some established multinationals, such as Apple, 3M, and GE, are already applying the principle of cost innovation to innovate faster, cheaper, and better (Radjou et al., 2012). Apple invests substantially less money than its peers in research and development, especially when its $R \& D$ spending is measured as a percentage of revenue. In an interview with Fortune in 1998, Steve Jobs noted: "Innovation has nothing to do with how many R\&D dollars you have. When Apple came up with the Mac, IBM was spending at least 100 times more on R\&D. It's not about money. It's about the people you have, how you're led, and how much you get it". GE, meanwhile, used cost innovation to launch two revolutionary products in 2009 - a US\$ 1,000 handheld electrocardiogram device and a portable, PC-based ultrasound machine that sells for as little as US\$15,000, which were welcomed not only in emerging markets, but also in developed countries (Immelt et al., 2009).

The importance of cost innovation has led researchers to ask the next logical question: How can we enable cost innovation? In their book, Zeng \& Williamson (2007) suggested that Chinese firms are able to pursue cost innovation mainly because of their superior access to 
low cost and favorable resources in China. First, the talent pool available to Chinese companies at low cost is unprecedented in history. While China's growth has prompted more than 500 million people to move from working the land into the manufacturing and services sectors, the rural labor force still numbers over 450 million, roughly two-thirds of the total workforce. More importantly, China surpassed the United States in total enrolment in universities in 2006, so it now has more people studying for degrees than any other country in the world. Since then, the number of graduates from Chinese universities and colleges has passed seven million per annum. The most popular majors were among the most relevant to the needs of commerce and industry: business administration is the top choice, followed by computer science, law, finance, communications, medicine, and English.

Second, many Chinese firms enjoy access to state assets and intellectual property (IP) without having to pay the full market value that these assets might command if they were traded in an open global market (Fang et al., 2017; Walder, 1995). In most cases, the fact that Chinese companies have been able to access assets and IP at a discount reflects China's policy of achieving long-term transformation from central planning to a market economy, and its drive to improve the utilization of its national asset base, combined with asset and financial markets that are still underdeveloped by world standards.

Third, a peculiarity of China's corporate structures is that they often lead to a greater separation between ownership and control, and more management autonomy in practice, than in many U.S and European companies (Zeng and Williamson, 2007). This means that management has the elbow room to make decisions quickly, largely independent from constraints imposed by shareholders. Despite common perceptions in the West that most Chinese companies are state-run bureaucracies, and therefore handicapped from competing in the global market, quite the opposite is true: The fact that China is in the process of transitioning from central planning to a "market system with Chinese characteristics" means 
that the managers of the emerging Chinese firms are well placed to act as entrepreneurs (Shen and Lin, 2009).

Finally, a high level of personal incentive completes the unique confluence of advantages enjoyed by emerging Chinese companies (Aharony et al., 2000; Guan and Yam, 2015). The fact that the senior management of China's emerging companies can become personally rich if they succeed in building a valuable global company, while their state affiliations often cushion much of the downside risk, encourages aggressive expansion and risk taking. Most of these managers know that they are unlikely to win big if they simply try to emulate their established global rivals. Their best chance is to innovate, and the obvious place to focus is on cost innovation because it plays to Chinese strengths.

Despite this progress in understanding the nature of cost innovation, studies designed to uncover what kind of organizational processes and capabilities can promote cost innovation are still lacking. In this paper, we aim to take a first step to filling this gap, by looking at how organizational processes can act as antecedents for cost innovation. We have chosen to analyze a set of case studies of Chinese firms pursuing cost innovation and then to explore some of the implications of these innovations for incumbent competitors from the developed markets. Synthesizing the findings from these case studies suggests a number of key processes by which latent needs can be uncovered and harnessed to fuel cost innovation.

In the first phase, Chinese firms search for innovation ideas by using customeroriented processes. These include: Establishing joint labs with lead customers, inviting members of customers' staff to participate the potential Chinese supplier's own R\&D, and collaborating with customers via the Internet. In the second phase, Chinese firms select which innovation ideas to take forward using pragmatic decision making, rather than becoming enamored with the technologies behind them. In the final phase, Chinese firms implement these innovation ideas using highly flexible product development processes, including 
adopting a flexible assembly line product development process and parallel engineering in product development.

In exploring these underpinnings and implications of cost innovation, this paper is structured as follows. The next section on methods and data explains the case study methodology we deploy to explore these issues and conjectures and how data were collected and analyzed to investigate the organizational processes that promote cost innovation. We then report findings from the case studies of Chinese firms, followed by a discussion of the implications for the changing nature of global competition. We conclude by outlining the possible contributions of the present study to existing theory and practice.

This study makes a number of important contributions. Theoretically, it is the first study in the cost or frugal innovation literature to explain the critical role played by organizational processes in creating cost innovation, where previous studies focused on the "input" factors in explaining the antecedents for cost innovation. This expands the theory of cost innovation in an important way. Moreover, it is the first study demonstrating that customer centricity in the context of product innovation can result in significant cost reduction, not only a better fit between functionality and customer needs. This is one important theoretical aspect of customer centricity that has not been examined by previous studies. Managerially, it is the first study that has clearly outlined three specific organizational processes: customer-oriented search process for innovation ideas, pragmatic decision making and flexible product development process, which a firm can follow in successfully creating cost innovation.

\section{Methods and data}

As we have already noted, evidence suggests that China is becoming an important 
source of cost innovation (Gadiesh et al., 2007; Schanz et al., 2011; Williamson, 2010; Williamson, 2009; Zeng and Williamson, 2007). Existing research also suggests a number of factors that encourage Chinese firms to focus on cost innovation, including: Low cost talent at all skill levels; low income in the majority of Chinese customers, encouraging focus on "good enough" or "sufficient" product performance on key attributes; shortage of capital investment; and lack of experience in traditional $R \& D$, focused on higher performance and extended functionality (Zeng and Williamson, 2007). The study of Chinese firms is therefore a potentially fertile ground for examining what organizational processes can be deployed to deeply understand customers' needs and convert these opportunities and demands into cost innovations.

In seeking to answer this question, we rely on inductive theory building using case study. The adoption of this approach is largely a function of the research questions that we are interested in. The case study has a distinct advantage in addressing "how" and "why" questions (Yin, 2003), and can "investigate a contemporary phenomenon in depth and within its real-life context, especially when the boundaries between phenomenon and context are not clearly evident" (Yin, 2003). Case studies, like experiments, can be generalized to form theoretical propositions. The goal of adopting the explanatory case study research to test theory is to expand and generalize theories (analytic generalization) and not to enumerate frequencies (statistical generalization). We chose multiple-case study methodology because it has proven particularly effective in developing new theory from consistent patterns within case data, using replication logic in which each case serves to confirm (or disconfirm) the emergent theory (Eisenhardt, 1989; Martin, 2011). Moreover, multiple case studies are more likely to yield more generalized, robust, and parsimonious theory than single-case studies (Langley, 1999; Yin, 2003). 
In sampling, we chose cases that we believed to be fairly representative of Chinese companies that have successfully enabled cost innovation by non-traditional organizational processes. Research sites were selected to achieve a diverse sample, and to enable richer theory development (Glaser and Strauss, 1967; Strauss and Corbin, 1990). We aimed to analyze a sufficient number of case studies and range of industries to be fairly confident that the results had some general applicability while limiting the sample so as to enable in-depth interviews within a tractable timescale. The resulting sample includes Chinese firms in industries as diverse as mobile phones, musical instruments, personal computers, and solar power. While studying these innovators is most likely to shed light on our research questions, they do not necessarily reflect the broader population of Chinese firms (Langley, 1999).

\subsection{Data collection}

We conducted a field study using observations, interviews, and archival data such as internal documents, annual reports, websites and news articles, in order to triangulate the data and so improve the accuracy of the picture emerging and ensure research validity (Jick, 1979). The primary data take the form of semi-structured interviews with highly knowledgeable persons in case firms at three hierarchical levels: Corporate executives; senior managers; and business unit informants. The secondary data covered field observations, media documentation, company websites, and documents provided by the interviewees. To strengthen the research reliability, all of the interviews were conducted face-to-face, taking between thirty minutes and two hours. Interview notes were written down immediately after each interview, normally within 24 hours. Each note was reviewed by two other researchers to ensure the proper understanding of the informants.

By the end of the research program we were successful in conducting two rounds of interviews across 14 companies (Table 1 presents an overview of the case sample). The first round of interviews was conducted between March 2010 and December 2011 and a second 
round between July 2013 and October 2014. The second round of interviews complemented the first by asking follow-up and clarification questions. In some cases, we were able to secure interviews with multiple individuals; here we tried to gain perspectives from employees drawn from different levels in the corporate hierarchy, or multiple business units, making a total of 39 semi-structured interviews. We started the interviews by asking background questions, such as the name of the informant, their role in their firm, and how many years they had worked with their firm. We encouraged informants to provide more details when their descriptions were brief, or when novel strands of narrative emerged (Martin and Eisenhardt, 2010; Strauss and Corbin, 1990). Data collection stopped when theoretical saturation was reached (Strauss, 1987). Data about unconventional organizational processes to enable cost innovation were compared and integrated across interviewees.

\subsection{Data analysis}

We used within-case and cross-case analyses following recommendations for multiple-case studies (Eisenhardt, 1989; Miles and Huberman, 1994). We started by writing up individual cases that triangulated all of our data including observations, interviews and documents (Jick, 1979). The importance of within-case analysis is driven by one of the realities of case study research - an overwhelming volume of data. We began within-case analysis by developing preliminary concepts and a rough theoretical explanation for the preconditions of cost innovation. Detailed individual case write-ups for each site gave us a deep familiarity with each case which, in turn, accelerated cross-case comparison. After that we conducted a cross-case analysis using replication logic across firms, treating each firm as a case.

The inductive analysis aimed at identifying themes from within the embedded cases and comparing these findings across cases. The grounded theory approach was reflected in the construction of categories of findings by developing categories of information (open 
coding), interconnecting the categories (selective coding), and building a story that connects the categories (axial coding), upon which the final findings are based (see Table 2) (Strauss and Corbin, 1990). The construction of categories can therefore be seen as an iterative process that establishes common meaning across multiple observations (Locke, 2001). Some novel conceptual constructs and new theoretical relationships were revised or deleted if we found they did not replicate across the cases. Using replication logic, we did not undertake data analysis until we reached a strong match between emergent theory and the empirical data.

\section{Case study findings}

The three categories of organizational processes underpinning the cost innovation that emerge from our data analysis are shown in Table 2. These were: Searching cost innovation ideas by customer-oriented processes such as establishing joint labs with customers, adding customers as key members of the R\&D team, and involving customers in the R\&D processes through the Internet; selecting cost innovation ideas by pragmatic decision making; and implementing cost innovation ideas by flexible product development processes such as industrializing, or introducing parallel engineering into the product development process.

During our fieldwork, we found many other Chinese firms outside our sample that did not understand the principles of cost innovation. Some Chinese firms were able to develop new technological capabilities, but failed to link the development of such technological advances to changes in the marketplace, in consumer needs or market conditions. Other Chinese firms only relied on low factor costs to offer the lowest possible prices in a "race to the bottom". This suggests that firms that use a deep understanding of their customers' latent needs to leverage the abundant resources and low factor costs available in China in novel ways are making a conscious strategic choice to try to gain advantage against competitors 
who enjoy similar access to abundant and low-cost resource pools. In what follows we detail the organizational processes that fuel cost innovation in China.

\subsection{Searching by customer-oriented processes}

Understanding customer requirements and market trends is the early phase of the product development process, which includes the identification of product opportunities and the specification of products (Khurana and Rosenthal, 1998; Zhang and Doll, 2001). This early phase plays a particularly important role in cost innovation, because such innovation aims to save cost by only developing enough and specific features for their customers. This is different from traditional innovation in Western countries, with abundant budget often leading companies to overshoot and develop features that customers may not need (Christensen, 1997; Gadiesh et al., 2007; Wan et al., 2015).

Establishing joint labs with customers. Some Chinese firms we studied enabled cost innovation by setting up joint innovation centers with customers to deepen understanding of the customers' latent needs and develop products meeting the specific needs of customers at low cost. For example, Kingdee (listed on the Hong Kong Stock Exchange), a leading Chinese ERP (Enterprise Resource Planning) software provider, was established in 1993 to develop accounting software. At that time, SAP and Oracle dominated the Chinese ERP industry. Kingdee started to develop ERP system K/3 for SMEs in 1997. By learning from CASE (acquired by Kingdee) and Microsoft, the performance of K/3 improved dramatically and it became a leading ERP system in China. Kingdee has also been developing a large ERP system named EAS (Enterprise Application Suite). Kingdee started to develop EAS in 2003, and by 2010 EAS had been implemented in several hundred large Chinese enterprises, many of which were listed in Shanghai Stock Exchange or Shenzhen Stock Exchange. By 2008 Kingdee had released a comprehensive set of ERP systems covering all levels of customers 
with EAS for big enterprises, K/3 for SMEs, and KIS (Keep It Simple) for small enterprises. According to the report by $\mathrm{CCW}^{1}$, in 2008 Kingdee was the second biggest ERP supplier (next to another Chinese ERP supplier Yonyou) in the Chinese market, surpassing SAP and Oracle.

To understand customers' latent needs, Kingdee established joint innovation centers with its major clients, including GREE group (listed on the Shanghai Stock Exchange), GNG (listed on the Hong Kong Stock Exchange), and WENS group. The joint innovation centers help Kingdee to deeply understand the customers' needs and develop specific products or solutions for Chinese companies. One such disruptive product is the Kingdee BOS (Business Operating System), which is an ERP software deployment platform that allows Chinese companies to customize the ERP application by themselves according to their specific management condition. Because different companies normally have some unique management practices, implementing ERP software is much more than simple installation, but involves deep customization at high cost (often lasting several years of working with ERP vendors). This may not be a problem for established firms in developed countries, but for many emerging Chinese companies with limited capital at their disposal, the high cost of implementation and maintenance of ERP software is a handicap. Understanding this latent need among Chinese customers, the Kingdee BOS disrupted the Chinese ERP industry by dramatically simplifying the implementation processes and lowering the investment required. As a senior R\&D manager noted:

The BOS application is our core competitive advantage when competing with established multinationals. The application is easy to use so our clients are able to customize and maintain their ERP system

\footnotetext{
${ }^{1} \mathrm{CCW}$ (China Computer World) report of the Chinese management software sector, 2009. CCW, a joint venture magazine between IDG (a leading IT media based in the US) and Chinese Ministry of Science and Technology, is a top IT magazine in China.
} 
according to their specific needs by themselves, which would dramatically save their cost.

Another example is Huawei, headquartered in Shenzhen, China. It was founded in 1987 as a distributor of imported telecoms products with an initial registered capital of merely USD 3,000. Since then the company has succeeded in disrupting the telecoms industry by offering telecommunications equipment to operators with adequate functionality and reliability that could be installed rapidly, customized easily to local requirements, and serviced remotely, all at a lower price than its major competitors. This enabled it to become the largest telecommunications equipment maker in the world, having overtaken Ericsson in 2012 (Economist, 2012). Its telecoms products and services have been deployed in more than 140 countries and it currently serves 45 of the world's 50 largest telecoms operators.

In order to deeply understand the customers' needs, Huawei has established joint labs with its major clients, including Deutsche Telecom, Vodafone, Telefonica, China Telecom, and China Mobile. Those joint labs have released some very successful products and solutions. For example, the telecom infrastructure keeps upgrading - from 2G, 2.5G, $3 \mathrm{G}$ to the latest $4 \mathrm{G}$ network - which meet different needs of various telecom vendors at different stages. However, each upgrade of the network often led vendors to completely redeploy their network infrastructure. This is not only time consuming, but also incurs substantial cost. Understanding this customer problem, and by working with its clients in the joint labs, Huawei disrupted the telecom infrastructure industry by the SingleRAN solution, which allows operators to support multiple mobile communications standards and wireless telephone services on a single network. By using the SingleRAN solution, telecom vendors are able to upgrade their networks with only minor changes and without replacing their network infrastructure, which means upgrade costs are lowered dramatically. As a senior director explained: 
Many people asked me the question of what is unique about innovation in Huawei. I would say customer focus in innovation is the key... For example, the SingleRAN concept was first developed in our joint labs with our clients to offer a single network infrastructure, single deployment, and single maintenance solution at low cost, it would be difficult for us to develop such a solution without working closely with our clients.

By establishing joint innovation centers with clients to deeply understand the customers' needs, some Chinese companies are able to develop the products and processes necessary to exploit opportunities for cost innovation at much lower levels of investment than using traditional strategies designed to innovate on the basis of more sophisticated products. Joint innovation centers lower the cost of innovation by sharing innovation investment with the clients. More importantly, joint innovation centers facilitate developing the right products to meet the exact needs of customers. Only listening to what customers say about what they want is not enough to understanding the latent needs of customers, because "We can know more than we can tell" (Nonaka, 1994; Polanyi, 1966). In joint innovation centers, companies co-locate with clients under the same roof, reinforcing their ability to recognize customer needs, to access customers' intelligence, and to combine or meld these into a creative business concept or an innovative product or service. Establishing joint innovation centers with clients therefore enabled some Chinese companies to bring products to meet key demand of mainstream, mass-market consumers at lower prices than competitors.

Including customers as key members in the R\&D team. We also found that some leading Chinese firms, such as Sany, adopted a different approach to understand customers' latent needs by adding customers as key members of their R\&D team. Founded in 1986, Sany is a Chinese multinational heavy machinery manufacturing company headquartered in Changsha, Hunan Province. The company went public on the Shanghai Stock Exchange on July 2003. Sany has acquired two German firms, Putzmeister and Intermix, and entered a joint venture with Palfinger of Austria. Now Sany has a dozen industrial sites in China plus 
manufacturing facilities in Brazil, Germany, India, Indonesia, and in the United States. By combining the technical know-how obtained from western companies, the deep understanding of customers' needs, and low cost, Sany has disrupted the construction equipment industry. It has now become the second largest heavy equipment manufacturer in the world, and the first Chinese company in this industry to enter the FT Global 500.

A distinctive part of Sany's innovation processes is its policy of inviting major clients to become key members of its R\&D team. In the planning stage of new product development, Sany joins equipment operators and sales agents with its own R\&D staff to form a team to evaluate the product design and finalize new features. Although Sany conducts most of the work in the development stage, in the final stage of testing new products, it is their customers, not Sany, who approve and release new products. Other companies may also try to involve customers in the innovation processes, but it is rare that customers take the role of approving and releasing new products. As a product manager in Sany mentioned:

Since clients are using our products every day, they know best the pros and cons of our products...letting our customers in charge of testing new products is very challenging, but it's worth it as the products released would meet our customer needs $100 \%$.

$\mathrm{XCMG}$ - another leading Chinese construction equipment manufacturer - applied the same approach to deeply understand customers' needs. XCMG is a multinational heavy machinery manufacturing company headquartered in Xuzhou, Jiangsu. It is a state-owned company, founded in 1989, which is listed on the Shenzhen Stock Exchange. In 1995, XCMG formed a joint-venture with Caterpillar. In the same year, XCMG and Liebherr Group signed a licensing agreement, allowing XCMG to manufacture three models of Liebherr allterrain cranes. Since then XCMG has achieved rapid growth. In 2012 XCMG acquired a majority stake in the privately owned German machinery manufacturer Schwing. In that year 
the company began construction of a 16,400-square meter research and development facility in Krefeld, Germany. By 2014, it ranked fifth in the world construction machinery industry.

XCMG often invite customers to join the R\&D process so as to understand their specific needs and develop new products to meet them. One example is the popular EBZ200R hard rock tunnel-boring machine. Traditional excavation and tunneling methods include blasting and shield tunneling construction. Blasting is dangerous and often causes some degree of collateral damage; while shield-tunneling construction only suits large-scale projects, because the initial installation of the device itself involves very high cost. Some clients suggested developing a boring machine to replace blasting or shield-tunneling construction in order that they could avoid these problems. XCMG invited key customers to join their $R \& D$ team to improve the existing boring machine models. This resulted in the release of the EBZ200R hard rock tunnel boring machine, with a high strength cutting head with optimized cutter arrangement. The EBZ200R hard rock tunnel-boring machine delivered greatly-enhanced rock crushing performance and dramatically lowered the cost of digging and tunneling, compared with competing products and solutions.

The practice of involving users and customers in the innovation process has long been a subject of research (Bogers et al., 2010; Smith, 1776/1999; von Hippel, 1986, 1998). This suggests two plausible explanations why users invest in co-innovation with suppliers. Innovation that combines technical knowledge with knowledge of user needs often results in new products that better fit their needs. Von Hippel (1994), meanwhile, argues that users are in a better position than producers to innovate if knowledge of user needs is "sticky", or costly to transfer. Hence, by sharing their unique knowledge and expertise, customers can improve the chances of creating low-cost innovative solutions, tailored to their specific needs (Franke and Shah, 2003; Slaughter, 1993).

Collaborating with customers in the $R \& D$ processes through the Internet. We 
observed that involving customers in the $R \& D$ processes through the Internet was another approach adopted by Chinese firms to enable cost innovation. One example is Xiaomi Technology, a privately owned Chinese electronics company headquartered in Beijing. The company was co-founded by eight partners on June 6, 2010, and it is now one of China's biggest electronics companies, designing, developing and selling smartphones, mobile apps and consumer electronics. Since the release of its first smartphone in August 2011, Xiaomi has gained market share rapidly in mainland China. Xiaomi employs a business model that is very unlike other smartphone makers, such as Samsung and Apple. At the time of writing, the company does not own a single physical store and instead sells exclusively from its own online store. It has also done away with traditional advertising and relies on social networking services and customer word of mouth to help advertise its products. According to IDC, in 2014 Xiaomi became the third largest smartphone maker in the world, after Samsung and Apple.

The secret of Xiaomi's success is its capability to continually upgrade the operating system in its smartphones, enabling them to meet the needs of smartphone enthusiasts who are eager to enjoy the latest applications and potential new functionality. Like some leading smartphone manufactures, Xiaomi upgrades the operating system frequently - since August 2010 Xiaomi has released more than 100 new versions. Xiaomi is able to achieve this rapid cycle of relevant innovation by involving key customers in the development processes. The company has established a social network for smartphone enthusiasts that includes more than two-hundred-thousand active members. These smartphone enthusiasts work with Xiaomi's $R \& D$ team to develop and test the latest version of operating system. As an R\&D manager at Xiaomi explained:

For a company, a R\&D team usually consists of 200 to 300 engineers at most. But if you extend your R\&D activities through the Internet, there will be hundreds of thousands of people helping you to design, 
development, and test your products for free.

Another example is Haier Group, a Chinese multinational home appliances and consumer electronics company headquartered in Qingdao, China. The company was founded in 1984 and is listed on both the Shanghai and Hong Kong Stock Exchanges. In 2014, research firm Euromonitor announced that Haier had become the number one Global Major Appliances Brand in the world for the fifth consecutive year, increasing its global market share to $10.2 \%$. One of the main reasons for Haier's success is that their products meet the specific needs of local customers. In order to understand precisely what customers want, Haier launched an Internet platform to involve customers in the whole R\&D process. One of the fruits of this strategy was their award-winning air conditioner "DiZun", released with the continuous help of hundreds of thousands of members on the Internet platform, who provided feedback during the design process.

This approach can be effective because cost innovation often arises from continuous cycles of upgrading (Williamson and Yin, 2009). A disruptive product often starts out as inferior in terms of overall performance compared with dominant designs, and can only serve niche segments that value its non-standard performance attributes (Markides, 2006). By continuously upgrading a product based on an understanding of customers' latent needs, it can evolve so as to become "good enough" in performance to satisfy mainstream customers while being cheaper to produce by focusing solely on key attributes (Markides, 2012). Collaborating with customers in the $R \& D$ processes via Internet provides a way for continuous upgrading of a product at low cost.

3.2 Selecting innovations through pragmatic decision making

The traditional decision-making processes in selecting innovation ideas, that have 
become embedded in many global corporations, understandably reflect the demands of the mature markets for which they were developed. In these markets legacy customers are often cautious, while regulatory constraints and risk aversion all militate against the launch of new products or business models until these have been thoroughly researched and tested. Rules, regulations and "standard operating procedures" originally designed for routine activities have permeated many large companies including the supposed crucible of creativity: R\&D. Meanwhile, the move away from traditional corporate hierarchies towards so-called "flat organizations" has necessitated extensive consensus building, involving key members of every department or team that might be impacted, before radical changes are decided upon and implemented. Such consensus building is generally time consuming, because each different department has their own agenda in mind and is prone to the pursuit of local optimization, rather than taking the perspective of what is best for the entire organization.

An increasing number of large companies are coming to recognize the problems associated with highly structured and corporate consensus-driven R\&D and innovation processes. leading them to engineer a shift towards more decentralized models that enable more localized and rapid decision making. General Electric's disruption of its own internal structure and processes is a good example (Immelt et al., 2009). Hamel (2007) has gone even further, suggesting that innovation will lead to competitive advantage primarily when it is based on a novel management principle that challenges some long-standing orthodoxy and is part of an on-going program of rapid-fire invention where progress compounds over time.

Interestingly, in our sample of Chinese firms, we observed that their organization structures tended to be more hierarchical than is the norm observed by researchers in Western companies (Rajan \& Wulf, 2006). We found that in Chinese firms a single, senior individual often overlooked the entire R\&D process and his or her word was proverbial "law" in making innovation decisions. Such dependence on the judgement of a single executive increases the 
risk that $\mathrm{R} \& \mathrm{D}$ efforts end up moving in a completely unproductive direction. But this hierarchical structure and decision making does speed up the process of initiating, developing and launching innovations. At the same time, we observed that the innovation processes adopted by Chinese companies provided extreme horizontal flexibility to marshal and recombine resources from different departments and functions across the organization behind a favored idea. Whenever a problem arose in the R\&D process the most common approach for Chinese companies is to call for an immediate meeting attended by the heads of relevant departments. A quick diagnosis was performed and solutions often swiftly decided upon, after which immediate action was taken by the participating party (in large part because of intense pressure from the vertical hierarchy on the entire group to deliver): A process that might be termed "huddle-and-act".

Chinese companies can, also, often afford to take decisions to back a potential innovation more quickly than firms in high-cost locations, because even moderate market success will take them beyond their lower break-even levels. The economics of creating a new mobile phone again provides an instructive example from our case studies. For a company located in Europe or the USA, such as Apple, such a project needs to cover an investment of millions of dollars before it becomes profitable. Each new innovation project therefore represents a significant decision for which the probability of success must be thoroughly assessed before proceeding.

By using these pragmatic and rapid processes, we observed that Chinese firms were able to launch as many as 20 new models for the same total investment as their Western competitors. Each innovation represented a small, rapid-fire bet. Only a small proportion of these bets need to succeed in order to make the whole program profitable, so that each launch decision could be taken quickly, even if the available information is incomplete, allowing Chinese companies to respond to rapidly changing consumer preferences and fashion trends, 
and at low cost, and hence deliver cost innovation.

SIM Technology, the designer and manufacturer of cell phones based in Shanghai, offers a good example. After SIM Technology launched a handset with large font size and keypad buttons designed for senior citizens, it received requests to add an alarm function in case the user falls or becomes ill, and satellite tracking capability so relatives can locate elderly parents when they are away from home. Whenever it hits a roadblock during the process of creating a new product, it brings together experts across all the disciplines (hardware, software, industrial design, user interface and aesthetics, testing, procurement, and production). A combination of hierarchical vertical, but horizontally flexible organizational structures, low break-even points and a highly fluid home market with lighter regulation and less loyal customers more willing to experiment, therefore, has encouraged Chinese competitors to develop pragmatic decision-making processes that can identify cost innovation opportunities and launch them into the market quickly.

\subsection{Implementation using flexible product development processes}

Traditional product development processes are designed to innovate on the basis of improved functionality or more sophisticated products. The uncertainty during these processes requires traditional innovators to follow a step by step approach in product development, because the information necessary to shape the next step may be incomplete or unavailable until an earlier step is finalized. But for cost innovation, where the underlying technology remains unchanged, this risk is relatively small. Because the overall architecture of the tasks to be performed and the interfaces are already pre-defined by a standardized approach, it is not always necessary to work sequentially. We found that some Chinese firms adopt flexible product development processes to enable cost innovation, including industrializing and introducing parallel engineering to the product development process. 
Industrializing the product development process. Some Chinese firms we studied have enabled cost innovation by industrializing the product development process and adopting an "assembly-line" approach analogous to that used in manufacturing. Taking the example of Huawei again, in order to complete a complex R\&D task, the company often finely divides the process down into a multitude of specific activities. It then assigns an engineer, or even a group of engineers, solely to that specific mini-task. So that while a company like Apple might dedicate a total of 10 engineers to a particular R\&D project, Huawei would assign a 100-person team to the same opportunity. By increasing the total number of researchers and assigning each individual or small team to a narrowly defined task within its "R\&D assembly line", Huawei has been able to reduce the cost to complete a project. The large supply of qualified engineers available in China allows companies like Huawei to gain economies of scale and labor specialization in R\&D; important factors that can improve efficiency and lower cost in a company (Lado et al., 1992; Porter, 1980, 1985). This industrialized R\&D process is poorly suited to "traditional innovation," which typically focuses on developing completely new technologies or substantially pushing forward the boundaries of functionality, but it does appear to work well when the aim is to disrupt incumbents who have created performance overshoot, by providing sufficient functionality with improved value for money, greater reliability, flexibility or shorter cycle times. In other words, it is well suited to cost innovation.

By industrializing the product development processes in these ways, to leverage the huge pool of engineers and other staff available in China, Chinese companies are able to develop the products and processes necessary to exploit opportunities for cost innovation at much lower levels of investment, and more rapidly than using traditional R\&D processes designed to innovate on the basis of improved functionality or more sophisticated products. Industrialized $\mathrm{R} \& \mathrm{D}$ processes therefore enable Chinese companies to bring products adequate 
to meet the basic functionality and reliability demanded by mainstream, mass-market consumers with a wider choice of incremental features and more customization, faster and at lower prices than competitors using traditional innovation processes are in a position to deliver.

Parallel engineering in product development. We found that some leading Chinese firms, such as Lenovo, adopted a different approach to facilitating cost innovation, borrowing not from the concepts of assembly lines used in manufacturing, but from the idea of "parallel processing" commonly used in supercomputers. Lenovo is a Chinese multinational technology firm with headquarters in Beijing, China and Morrisville, North Carolina, United States. The company was founded in Beijing in 1984 as a reseller and distributor for foreign brands such as IBM. In 1990, Lenovo started to manufacture its own personal computers (PCs) and by 1997 became the market leader in China over international leading firms such as Dell, HP and IBM. In 2004, Lenovo made a strategic choice to expand abroad and bought IBM's PC business (including the brand ThinkPad) for USD 1.25 billion. The company then disrupted the global PC sector by supplying the IdeaPad computers, which target home customers, and the ThinkPad computers (many are simpler versions of the original ThinkPad models), which target business customers at low price and became the world's second-largest personal computer vendor by unit sales (Gartner, 2013).

Following their acquisition of IBM's personal computer business back in late 2004, Lenovo adopted many of the R\&D disciplines and procedures IBM had developed over decades of successful innovation. But Lenovo also modified the IBM R\&D blueprint by introducing a parallel-processing approach. Instead of treating $R \& D$ as a linear process, Lenovo began to create a new $R \& D$ process that allows various functions that are normally sequential steps to be conducted simultaneously.

The concept of simultaneous engineering is certainly not new (Clark and Fujimoto, 
1991), but in the Chinese cost innovators we studied it had been adopted more extensively than appears to be the case in most incumbent firms, involving more development stages and greater timing overlaps. Pushing this parallel processing in the innovation process beyond accepted limits clearly carries risks, not least because the information necessary to shape the next step may be incomplete or unavailable when the tasks are undertaken in parallel. But for cost innovation where the underlying technology remains unchanged this risk is relatively small. Because the overall architecture of the tasks to be performed and the interfaces are already pre-defined by a standardized approach, it is not always necessary to work sequentially. Instead, much of the work can proceed in parallel, relying on standardized interfaces to make sure the results of each task come together in a coherent whole. Parallel engineering in the product development process has facilitated cost innovation by reducing the total time and cost required to develop a product that offers greater value for money to consumers.

\section{Conclusion}

Cost innovation is a new pattern of innovation that has emerged not only in developing countries but also in developed countries in recent years. Existing research has explored the nature of cost innovation and the market conditions in which it is likely to arise. There has been much less investigation, however, of the nature of the organizational processes that might facilitate cost innovation. An analysis of the antecedents of cost innovation from China, therefore, promised to shed light on how the organizational processes adopted by a firm alter the probability of launching successful cost innovations.

Based on multiple case studies of Chinese firms, we found that their adoption of new, or somewhat unconventional, organizational processes did seem to facilitate the realization of 
various kinds of cost innovation. Specifically, searching for innovation ideas by using customer-oriented processes, selecting among potential innovations using pragmatic decision making, and implementing them through flexible product development processes, all appeared to underpin and facilitate cost innovation in our sample of firms.

Our research makes several theoretical contributions. Our results suggest that in understanding the antecedents of cost innovation it is not sufficient to explain the preconditions for cost innovation to emerge. These preconditions have been the focus of the existing literature, including: Low-cost talent at all skill levels, access to state assets and intellectual property at a discount, greater management autonomy versus shareholders than many of their Western counterparts, and strong personal incentives to create value (Zeng and Williamson, 2007). It is also important to model another important link in the logic chain: the organizational processes firms deploy to deeply understand the customers' latent needs and market conditions, and then turn these innovation opportunities into reality through pragmatic decision making and flexible product development processes.

First, our results suggest that searching for innovation ideas using customer-oriented processes can lead to cost innovation. Customer-oriented processes help a company to recognize customer needs, to access customers' intelligence, and to combine or meld these into a creative business concept or an innovative product or service. This plays a particularly important role in cost innovation because such innovation aims not only to develop the specific features of a product, but also to help customers save money, or enjoy a lower price point. This is different from the traditional innovation prevalent in Western countries with abundant budget, that often leads to performance overshoot and features that customers may not need.

Second, pragmatic decision making is also important to enable cost innovation. The traditional decision-making processes in selecting innovation ideas that have become 
embedded in many global corporations understandably often incur high cost by ensuring that new products or business models are thoroughly researched and tested before they are launched. This make sense where the innovations are radical or the risks are high. But by focusing on a different set of cost innovation opportunities, that require less investment and have lower risk, firms are able to make pragmatic decisions to launch more new models for the same total investment.

Third, flexible product development processes also play a key role in facilitating cost innovation. Industrializing and introducing parallel processing into product development processes helps firms to gain economies of scale and specialization in $\mathrm{R} \& \mathrm{D}$, which can lead to lower innovation costs. These kinds of development processes are well attuned to the requirements of cost innovation. They can therefore open the way to the provision of sufficient functionality with improved value for money, greater reliability, flexibility or shorter cycle times. By contrast, the flexible development processes are generally poorly suited to "traditional innovation" that focuses on developing completely new technologies or substantially pushing forward the boundaries of functionality.

Our results also extend the user innovation literature by examining how customeroriented processes can strengthen the link between users and prospective disruptors. The user innovation literature claims a direct link between interaction with customers and users and innovation performance (Lilien et al., 2002; von Hippel, 1986, 2005). The necessary knowledge flows promised by such a link, however, may be impeded when the contact with customers or users is through, for example, key account managers or the customer's purchasing department, rather than directly with the innovation team. The precise nature of customer involvement in these processes is, therefore, likely to be important (Foss et al., 2011). Our research suggests that customer-oriented processes such as establishing joint labs with customers, including customers as the key members in the R\&D processes, and 
collaborating with customers via the Internet can strengthen the link between users and organizations and are especially well-suited to cost innovation.

Our findings also have a number of managerial implications. First, they underline the need for managers to be alert to the important role of mechanisms to promote high-quality customer interaction in promoting cost innovation. While incumbent firms may have the capabilities to develop advanced technologies, it may not be easy for them to link their high technology products with the latent needs or the demands of potential new customers, because they often focus their investments on improving the established technologies used by their current customers. Customer-orientation is even more important for emerging companies whose resources are typically limited, because it allows them to focus these limited resources on developing and improving key attributes of their offerings that fit with the latent needs of potential mass-market segments.

Second, our findings also alert managers to the complexities of achieving effective links between users and their organizations. Understanding the customers' latent needs and finding potential new growth markets requires reliable customer-oriented processes that enable rich flows of knowledge between the potential customer and supplier and joint discovery. These include establishing joint labs with customers, including customers as key members of the $R \& D$ team, and collaborating with customers via the Internet for understanding how customers behave rather than simply how they say they will behave.

Third, our results point to the need for managers to be aware of the importance of pragmatic decision making in selecting innovation ideas to fuel cost innovation. While the traditional decision making processes for selecting innovation ideas that have become embedded in many global corporations aim to avoid innovation risks by thoroughly researching and testing innovation options, pragmatic and rapid decision making can facilitate potential cost innovation by reducing the total time and cost required to develop a 
product that offers greater value for money to consumers by incorporating uniquely marketrelevant features and performance, and offering these to consumers sooner than incumbents and at lower prices.

Finally, to fuel cost innovation, managers do not necessarily need to follow the step by step approach adopted in traditional product development processes. Given that in cost innovation, the overall architecture of the tasks to be performed and the interfaces are already pre-defined by a standardized approach, it is not always necessary to work sequentially. As a result, flexible product development processes such as industrializing or introducing parallel engineering to the product development process can play a key role in promoting potential cost innovation which aims to provide customers "good enough" products at lower prices.

\section{References}

Aharony J, Lee C, Wong T. 2000. Financial packaging of IPO firms in China. Journal of Accounting Research 38(1):103-126.

Bogers M, Afuah A, Bastian B. 2010. Users as innovators: A review, critique, and future research directions. Journal of management 36(4):857-875.

Christensen CM. 1997. The Innovator's Dilemma: When New Technologies Cause Great Firms to Fail. Harvard Business School Press: Boston, MA.

Clark KB, Fujimoto T. 1991. Product development performance: strategy, organization, and management in the world auto industry. Harvard Business Press.

Eisenhardt KM. 1989. Building Theories from Case Study Research. Academy of Management Review 14(4):532-550.

Ernst H, Kahle H, Dubiel A, Prabhu J, Subramani M. 2015. The antecedents and consequences of affordable value innovations for emeging markets. Journal of Product Innovation Management 32(1):65-79.

Fang L, Lerner J, Wu C. 2017. Intellectual property rights protection, ownership, and innovation: evidence from China. The Review of Financial Studies 30(7):2446-2477.

Foss NJ, Laursen K, Pedersen T. 2011. Linking customer interaction and innovation: The mediating role of new organizational practices. organization Science 22(4):980-999.

Franke N, Shah S. 2003. How communities support innovative activities: An exploration of assistance and sharing among end-users. Research Policy 32:157-178.

Gadiesh O, Leung P, Vestring T. 2007. The battle for China's good-enough market. Harvard Business Review 85:81-89.

Glaser BG, Strauss AL. 1967. The discovery of grounded theory: strategies for qualitative research. Aldine: Chicago.

Guan J, Yam R. 2015. Effects of government financial incentives on firms' innovation performance in China: evidences from Beijing in the 1990s. Research Policy 44(1):273-282. 
Guillen M, Carcia-Canal E. 2012. Emerging markets rule: Growth strategies of the new global giants. McGraw Hill: New York.

Immelt J, Govindarajan V, Trimble C. 2009. How GE is disrupting itself. Harvard Business Review 87(10):56-65.

Jick TD. 1979. Mixing qualitative and quantitative methods: triangulation in action. Administrative Science Quaterly 24(4):602-611.

Khurana A, Rosenthal S. 1998. Towards holistic "Front Ends" in new product development. Journal of Product Innovation Management 15:57-74.

Lado A, Boyd N, Wright P. 1992. A competency-based model of sustainable competitive advantage: toward a conceptual integration. Journal of management 18(1):77-91.

Langley A. 1999. Strategies for theorizing from process data. Academy of Management Review 24(4):691-710.

Lilien G, Morrison P, Searls K, Sonnack M, von Hippel E. 2002. Performance assessment of the lead user idea-generation process for new product development. management Science 48(8):1042-1059.

Locke K. 2001. Grounded theory in management research. Sage: Thousand Oaks, CA.

Markides C. 2006. Disruptive innovation: in need of better theory. Journal of Product Innovation Management 23:19-25.

Markides C. 2012. How disruptive will innovation from emerging markets be? Sloan Management Review 54(1):22-25.

Martin JA. 2011. Dynamic managerial capabilities and the multibusiness team: the role of episodic teams in executive leadership groups. organization Science 22(1):118-140.

Martin JA, Eisenhardt KM. 2010. Rewiring: cross-business-unit collaborations in multibusiness organizations. Academy of Management Journal 53(2):265-301.

Miles MB, Huberman AM. 1994. Qualitative data analysis: a sourcebook of new methods, 2nd ed. Sage: Beverly Hills, CA.

Nonaka I. 1994. A dynamic theory of organizational knowledge creation. organization Science 5(1):14-37.

Pandit D, Joshi M, Sahay A, Gupta R. 2018. Disruptive innovation and dynamic capabilities in emerging economics: evidence from the Indian automotive sector. Technological Forecasting and Social Change 129:323-329.

Polanyi M. 1966. The Tacit Dimension. Routledge \& Kegan Paul: London.

Porter ME. 1980. Competitive strategy. Free Press: New York.

Porter ME. 1985. Competitive advantage. The Free Press: New York.

Prabhu J, Jain S. 2015. Innovation and entrepreneurship in India: Understanding jugaad. Asia Pacific J Manage 32:843-868.

Radjou N, Prabhu J, Ahuja S. 2012. Jugaad innovation: Think frugal, be flexible, generate breakthrough growth. Jossey Bass: San Francisco, CA.

Ramamurti R. 2009. What have we learned about emerging market MNEs? In Emerging multinationals in emerging markets, Ramamurti R, Singh J (eds). Cambridge University Press: Cambridge, U.K.; 399-426.

Schanz C, Husig S, Dowling M, Gerybadze A. 2011. 'Low cost-high tech' innovations for China: why setting up a separate R\&D unit is not always the best approach. R\&D Management 41(3):307-317.

Shen W, Lin C. 2009. Firm profitability, state ownership, and top management turnover at the listed firms in China: a behavioral perspective. Corporate Governance: An International Review 17(4):443-456.

Slaughter S. 1993. Innovation and learning during implementation: A comparison of user and manufacturer innovations. Research Policy 22:81-95. 
Smith A. 1776/1999. An inquiry into the nature and causes of the wealth of nations. Penguin: London.

Strauss A. 1987. Qualitative analysis for social scientists. Cambridge University Press: New York.

Strauss A, Corbin JM. 1990. Basics of qualitative research: techniques and procedures for developing grounded theory. Sage: Newbury Park, CA.

Von Hippel E. 1986. Lead users: A source of novel product concepts. management Science 32(7):791-805.

Von Hippel E. 1998. Economics of product development by users: The impact of "sticky" local information. management Science 44(5):629-644.

Von Hippel E. 2005. Democratizing innovation. MIT Press: Cambridge, MA.

Walder A. 1995. Local governments as industrial firms: an organizational analysis of China's transitional economy. American Journal of Sociology 101(2):263-301.

Wan F, Williamson P, Yin E. 2015. Antecedents and implications of disruptive innovation: Evidence from China. Technovation 39-40(May-June):94-104.

Williamson P. 2010. Cost innovation: Preparing for a 'Value-For-Money' revolution Long Range Planning 43:343-353.

Williamson P, Yin E. 2009. Racing with the Chinese dragons. In China rules: globalization and political transformation, Alon I (ed). Palgrave Macmillan: New York; 69-100.

Williamson PJ. 2009. Value-for-Money Strategies for Recessionary Times. Harvard Business Review.

Yin RK. 2003. Case study research: design and methods. Sage: Newbury Park, CA.

Zeng M, Williamson PJ. 2007. Dragons At Your Door: How Chinese Cost Innovation Is Disrupting Global Competition. Harvard Business School Press: Boston, MA.

Zhang Q, Doll W. 2001. The fuzzy front end and success of new product development. European Journal of Innovation Management 4(2):95-112. 
Table 1

Overview of the Focal Firms

\begin{tabular}{|c|c|c|c|}
\hline Company & Brief History & Interviewees by Type & $\begin{array}{l}\text { Number } \\
\text { of Interviews }\end{array}$ \\
\hline Huawei & $\begin{array}{l}\text { (1) Founded in } 1987 \text { as a distributor of } \\
\text { imported telecoms products } \\
\text { (2) The largest telecommunications } \\
\text { equipment maker in the world in } 2017\end{array}$ & $\begin{array}{l}\text { Executives (1), } \\
\text { Managers (2), } \\
\text { Business unit informants (1) }\end{array}$ & 4 \\
\hline Kingdee & $\begin{array}{l}\text { (1) Established in } 1993 \text { to develop } \\
\text { accounting software } \\
\text { (2) Now one of the largest ERP software } \\
\text { suppliers in Chinese market, surpassing SAP } \\
\text { China and Oracle China }\end{array}$ & $\begin{array}{l}\text { Managers (2), } \\
\text { Business unit informants (1) }\end{array}$ & 3 \\
\hline SANY & $\begin{array}{l}\text { (1) Founded in } 1986 \text { as a material welding } \\
\text { supplier } \\
\text { (2) Now the world's second largest heavy } \\
\text { machinery manufacturer }\end{array}$ & Business unit informants (2) & 2 \\
\hline XCMG & $\begin{array}{l}\text { (1) Founded in } 1989 \text { as Xugong } \\
\text { Construction Machinery Science \& } \\
\text { Technology } \\
\text { (2) Now the world's fifth largest heavy } \\
\text { machinery manufacturer }\end{array}$ & Managers (2) & 2 \\
\hline Xiaomi & $\begin{array}{l}\text { (1) Founded in } 2010 \text { in Beijing } \\
\text { (2) Now the world's 3rd largest smart phone } \\
\text { distributor, after Apple and Samsung }\end{array}$ & $\begin{array}{l}\text { Managers (2), } \\
\text { Business unit informants (1) }\end{array}$ & 3 \\
\hline Haier & $\begin{array}{l}\text { (1) Founded in } 1984 \text { as Qingdao } \\
\text { Refrigerator Co. } \\
\text { (2) Now the world's largest company in } \\
\text { white goods, with } 10.2 \text { per cent market share }\end{array}$ & $\begin{array}{l}\text { Managers (2), } \\
\text { Business unit informants (1) }\end{array}$ & 3 \\
\hline SIM Tech & $\begin{array}{l}\text { (1) Listed on the Hong Kong Stock } \\
\text { Exchange in } 2005 \\
\text { (2) Leading mobile communication and } \\
\text { "internet things" developer in China }\end{array}$ & $\begin{array}{l}\text { Managers (2), } \\
\text { Business unit informants (1) }\end{array}$ & 3 \\
\hline Tianyu & $\begin{array}{l}\text { (1) Started as an OEM or a distributor } \\
\text { channel for leading brands } \\
\text { (2) Shanzhai products ranked second in the } \\
\text { Chinese mobile phone sector with } 16.1 \% \\
\text { market share in } 2012\end{array}$ & Business unit informants (2) & 2 \\
\hline Jinli & $\begin{array}{l}\text { (1) Started as an OEM or a distributor } \\
\text { channel for leading brands } \\
\text { (2) Shanzhai products ranked second in the } \\
\text { Chinese mobile phone sector with } 16.1 \% \\
\text { market share in } 2012\end{array}$ & Managers (2) & 2 \\
\hline Wide Group & $\begin{array}{l}\text { (1) Founded in } 1997 \\
\text { (2) Research, design and manufacture of } \\
\text { commercial air conditioning }\end{array}$ & $\begin{array}{l}\text { Managers (1), } \\
\text { Business unit informants (1) }\end{array}$ & 2 \\
\hline Alibaba & $\begin{array}{l}\text { (1) Founded } 1999 \\
\text { (2) China's largest e-commerce company }\end{array}$ & $\begin{array}{l}\text { Executives (1), } \\
\text { Managers (1), } \\
\text { Business unit informants (2) }\end{array}$ & 4 \\
\hline Wuxi & (1) Founded in 2000 & Managers (2), & 3 \\
\hline AppTech & $\begin{array}{l}\text { (2) One of the largest open-platforms for } \\
\text { pharmaceutical R\&D }\end{array}$ & Business unit informants (1) & \\
\hline Lenovo & $\begin{array}{l}\text { (1) Founded in } 1984 \text { as a reseller, distributor } \\
\text { for foreign brands } \\
\text { (2) Now the world's second-largest personal } \\
\text { computer vendor by unit sales }\end{array}$ & $\begin{array}{l}\text { Managers (2), } \\
\text { Business unit informants (2) }\end{array}$ & 4 \\
\hline Pearl River & $\begin{array}{l}\text { (1) Founded in } 1956 \\
\text { (2)Now the world's largest piano maker }\end{array}$ & $\begin{array}{l}\text { Managers (1), } \\
\text { Business unit informants (1) }\end{array}$ & 2 \\
\hline
\end{tabular}


Table 2

Enabling cost innovation coding scheme

Representative Informant Quotes

"The BOS application is our core competitive advantage when competing with established multinationals. The application is easy to use so our clients are able to customise and maintain their ERP system according to their specific needs by themselves, which would dramatically save their cost." (Kingdee)

"Many people asked me the question of what is unique about innovation in Huawei. I would say customer focus in innovation is the key..." (Huawei)

"Since clients are using our products every day, they know best the pros and cons of our products...letting our customers in charge of testing new products is very challenging, but it's worth it as the products released would meet our customer needs $100 \%$." (SANY)

"For a company, a R\&D team usually consists of 200 to 300 engineers at most. But if you extend your R\&D activities through the Internet, there wil be hundreds of thousands people helping you to design, development, and test your products for free." (Xiaomi Technology)

"We are very market driven or pragmatic in our decision making. For example, the foreign MNEs such as Nokia put a new mobile phone over 1,000 tests before it can be released to the market. However, we sense that the market desires speed. Therefore, we only pursue the most essential 200 tests to gain speed. Once our senior executive team made that decision. We immediately put it into practice to win the race" (SIM Technology)

"The process of developing a new drug is quite similar to that of an assembly line in manufacturing. We therefore divide the entire process into small bits, which are then staffed with people of varying degree of competence. Each group just concentrate on their own tasks and the entire process is managed by ERP system just like in a factory" (Wuxi AppTec)

"Parallel engineering is not new and has been employed by western firms for years, but we took this practice to another level. First, we involve more stakeholders in the parallel process to make it even faster; second, we often organize boot camps for the NPD teams when they race to finish a particular new product development project. Members from all divisions are put into a remote hotel where they work and eat there together. So, whenever there is a problem, it can be resolved immediately on the spot "

(Levono)

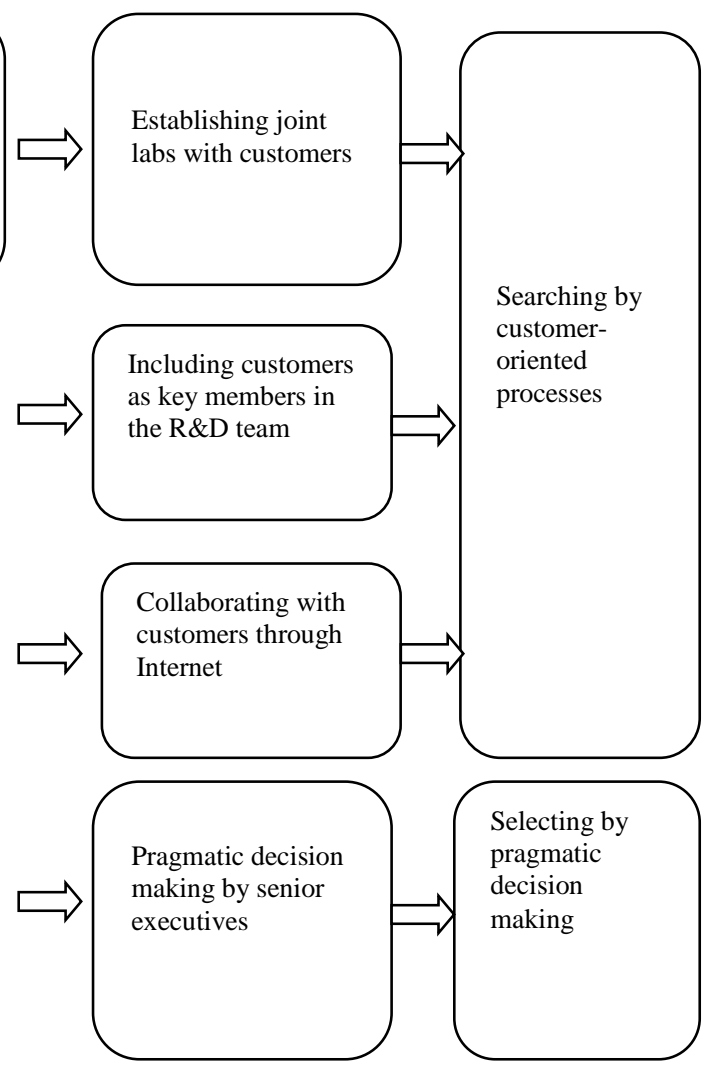

